\title{
Alpha Fetoprotein as a Marker of Severe Disease and Foetal Outcome in Pregnancy Induced
}

\section{Hypertension}

\author{
Ayokunle Moses Olumodeji ${ }^{* 1}$, Olumide Emmanuel Adewara ${ }^{2}$, Olabisi Timothy Adeyemo ${ }^{2}$, \\ Segun Murtala Ghazali ${ }^{3}$, Paul Olowoyo ${ }^{4}$ \\ ${ }^{1}$ Obstetrician \& Gynaecologist, Obstetrics and Gynaecology Department, Lagos State University Teaching Hospital, \\ Lagos, Nigeria. \\ ${ }^{2}$ Obstetrician \& Gynaecologist, Obstetrics \& Gynaecology Department, Federal Teaching Hospital, Ido-Ekiti, \\ Ekiti State, Nigeria \\ ${ }^{3}$ Head of Department, Chemical Pathology Department, Federal Teaching Hospital, Ido-Ekiti, Ekiti State, Nigeria \\ ${ }^{4}$ Cardiologist, Department of Internal Medicine, Federal Teaching Hospital, Ido-Ekiti, Ekiti State, Nigeria
}

*Corresponding author - Ayokunle Moses Olumodeji

Received 19 February 2019;

Accepted 07 March 2019;

Published 11 March 2019

\begin{abstract}
Background: Pregnancy-induced hypertension represents the most common medical complication of pregnancy and contributes significantly to maternal and neonatal morbidity and mortality. Many theories have been implicated in its genesis, crucial among which is the defective 2nd wave of trophoblastic invasion/placentation. Maternal serum alpha fetoprotein is a marker of placental abnormalities and may correlate with clinical features of significant management implications. This study evaluated the role of maternal Alpha-fetoprotein concentration as a marker of disease severity and foetal outcome in patients with pregnancy induced hypertension at the Federal Teaching Hospital, Ido-Ekiti, Ekiti state, Nigeria. Methodology: This was a prospective study in which 44 patients with PIH and 88 matched controls that satisfied the inclusion criteria were recruited using convenience sampling technique for cases and systematic random sampling for controls. Relevant socio-demographic, maternal medical and obstetric characteristics, alpha-fetoprotein levels and fetal outcome measures were obtained. A p-value of less than 0.05 was considered statistically significant. SPSS 20.0 statistical package (SPSS Inc, Chicago, IL, USA) was used for statistical analysis. Results: The prevalence of PIH in the study was $15.3 \%$. The difference in the mean $( \pm 2 \mathrm{SD})$ serum level of alpha fetoprotein (AFP) between the cases $(207 \pm 156.2 \mathrm{ng} / \mathrm{ml})$ and control group $(165.2 \pm 115.1 \mathrm{ng} / \mathrm{ml})$ was not statistically significant $(\mathrm{p}=0.079)$. The mean ( $\pm 2 \mathrm{SD})$ birth weight of babies born to women with PIH in this study was $2.7 \pm 0.6 \mathrm{~kg}$ which was significantly lower ( $<<0.001 ; 95 \% \mathrm{CI} 3.0-3.1)$ ) than the mean birth weights of $3.2 \pm 0.4 \mathrm{~kg}$ of babies of normotensive controls. The mean $( \pm 2 \mathrm{SD})$ Apgar scores at both 1 minute and 5 minutes were both significantly lower in the PIH group $(6.7 \pm 1.8$ and $8.4 \pm 1.5$ respectively) than among the normotensive women $(7.6 \pm 1.2$ and $8.9 \pm 1.1$ respectively). Thirty-one point eight percentage of babies born to women in the PIH group and $11.4 \%$ of babies of normotensive controls required admission into special care baby unit (SCBU) (Odds Ratio=1.17; 95\%CI (0.24-5.76) Serum AFP had a reasonable negative correlation with both birth weight ( $\mathrm{r}=-0.47$, $\mathrm{p}=0.001)$ and Apgar score at 5 minute $(\mathrm{r}=-0.44, \mathrm{p}=0.002)$. At 2 MoM serum AFP level, sensitivity and specificity for severe PIH were $36 \%$ and 90\% respectively. Conclusion: Maternal serum AFP levels showed reasonable positive correlation with disease severity and adverse fetal outcome that warrants further investigation. Maternal serum AFP can be useful in identifying pregnant women with PIH at risk of having severe disease and adverse foetal outcome.
\end{abstract}

\section{Introduction}

Pregnancy Induced Hypertension is a form of high blood pressure characteristically developed during pregnancy. It is defined as hypertension with or without proteinuria emerging after 20 weeks gestation, but resolving not later than 12 weeks postpartum. ${ }^{[1]}$ It is common and forms a deadly triad along with hemorrhage and infection which contribute greatly to maternal and fetal morbidity and mortality particularly in developing countries. ${ }^{[2]}$

Despite active research for many years, the aetiology of PIH remains unknown. The current hypothesis regarding the etiology of pre-eclampsia focuses on mal-adaptation of the immune responses and defective trophoblastic invasion. ${ }^{[3]}$ Thus, an excessive maternal inflammatory response, perhaps directed against foreign fetal antigens, results in a chain of events including shallow 
trophoblastic invasion, defective spiral artery remodeling, placental infarction and release of pro-inflammatory cytokines in the systemic circulation with widespread endothelia dysfunction. ${ }^{[3]}$

Amidst numerous biomarkers studied in pre-eclampsia, unexplained elevation of maternal serum alpha-fetoprotein (MSAFP), as a marker of placenta dysfunction, has also been associated with several placenta-mediated adverse pregnancy outcomes, including pregnancy induced hypertension, intrauterine growth restriction, and stillbirth. ${ }^{[4]}$ Despite significant association of MSAFP with severity of pregnancy induced hypertension and poor fetal outcome noted in some studies, ${ }^{[5-7]}$ this has not been uniformly accepted or confirmed across different populations. ${ }^{[8,9]}$

While the prevention of the disease is still elusive, it seems possible that some biomarkers like AFP may correlate with disease severity and help predict adverse pregnancy outcome in pregnancy induced hypertension. This may allow for timely intervention before the onset of complications.

Given the significant impact of pregnancy induced hypertension on maternal and fetal well-being this study aimed to determine the association between maternal serum alfa-fetoprotein and pregnancy induced hypertension compared with age- and parity- matched normotensive pregnant subjects.

\section{Materials and methods}

This was a hospital-based, case-control study, carried out in the Department of Obstetrics and Gynaecology of the Federal Teaching Hospital, Ido-Ekiti, Ekiti State, Nigeria. Forty four cases and 88 controls were selected using a case to control ratio of 1:2. We compared serum levels of Alpha-fetoprotein in women with pregnancy induced hypertension (cases) with those of healthy normotensive pregnant women (controls). Cases and controls were matched in age, parity and gestational ages and timing at diagnosis. The recruitment and follow-up process lasted for a period of ten months (1st August, 2016 - 31st May 2017). The patients were adequately counselled about the study and thereafter an informed consent was obtained before they were recruited into the study. Cases were recruited by convenience sampling technique while controls were recruited using systematic random sampling.

The study population consisted of singleton pregnant women between 20 and 42 weeks of gestation or in labour with pregnancy induced hypertension. Patients suspected or confirmed with any of the following conditions associated with elevated or reduced maternal serum Alpha-fetoprotein such as: Multiple gestation, Placental abruption, Fetal abnormalities such as neural tube defects including spina bifida and anencephaly, and abdominal wall defects, Foetuses with Down syndrome and Trisomy 18, Acute hepatitis, Diabetes Mellitus and Tumors such as endodermal sinus tumor, neuroblastoma, hepatoblastoma, and hepatocellular carcinoma were excluded from the study.

History was taken to ensure that the patient fulfilled the selection criteria and a thorough clinical examination was carried out. A structured proforma was used to obtain relevant data from each patient. Data obtained from the subjects and controls included age, tribe, educational status, occupation, parity, gestational age and history of hypertension, renal disease and history of PIH in previous pregnancies. The severity and type of pregnancy induced hypertension was noted in the subjects. The result of the serum Alpha-fetoprotein concentrations determined from the samples of the subjects and control taken at the time of diagnosis was equally recorded on the proforma. The estimated gestational age at diagnosis in the subjects were matched with controls using a matching factor of + or -1 week. Parameters compared between the subjects and the controls were their mean serum Alphafetoprotein at diagnosis of pregnancy induced hypertension and possible correlation with the disease severity and fetal outcome. Subjects recruited during the antenatal period were followed up till delivery with their matched controls. Subjects recruited in labour were matched with controls in labour. Severe PIH in the study was defined as a systolic blood pressure of $160 \mathrm{mmHg}$ and/or diastolic blood pressure of $90 \mathrm{mmHg}$.

The birth weight of each baby was determined within 30 minutes of delivery. The Apgar scores in the first and fifth minutes of life was determined using the Apgar scale devised by Virginia Apgar in $1952 .^{[10]}$

Five milliliters $(5 \mathrm{mls})$ of venous blood was drawn from the forearm vein of the selected patients under aseptic condition by the investigator or any of the research assistants following normal protocol. The collected blood sample, in a plain (non-heparinized) specimen bottle, was allowed to clot spontaneously and the serum separated after centrifugation at 3000rpm for 15 minutes in the chemical pathology laboratory. The samples were then refrigerated at 2-8oC until analysis. The serum analysis of alpha-fetoprotein was performed in conjunction with a Chemical pathologist at the Federal Teaching Hospital, Ido-Ekiti. The assay of serum Alphafetoprotein was done by ELISA using commercially manufactured ready to use kit by Monobind Inc. Lake Forest. CA 92630. USA.

\section{Ethics}

Ethical clearance for the study was obtained on the 6th of January 2016, from the Ethical and Research Committee of the Federal Teaching Hospital, Ido-Ekiti, Ekiti State, Nigeria, before commencement of the study. An ethical clearance certificate of protocol number ERC/2015/03/07/16A was issued as ethical approval for the study. This research has not been published journal or presented to another journal for publication. The researcher claims no conflicts of interest.

\section{Statistics}

The data and information obtained from the study were processed using statistical package for social sciences version 20 (SPSS Inc., Chicago, Illinois, USA). Frequency tables were generated and the results tested for statistical significance using odds ratio, chi-square and student t-test where appropriate. Tests of association were determined using logistic regression models. The receiver operating characteristic (ROC) analysis was used to obtain sensitivity and specificity. The level of statistical significance was set at $\mathrm{p}$ value $<0.05$ at $95 \%$ Confidence Interval.

\section{Results}

Prevalence of Pregnancy induced hypertension: The total number of cases of pregnancy induced hypertension admitted during the period of the study was 62. Forty-four of these women were recruited as cases, 15 did not meet the study inclusion criteria, and 3 did not consent to take part in the study. A total of 405 deliveries were recorded during the study period. The prevalence of pregnancy induced hypertension in the study was $15.3 \%$. 
International Journal of Innovative Research in Medical Science (IJIRMS)

Volume 04, Issue 03, March 2019,

https://doi.org/10.23958/ijirms/vol04-i03/599

Table 1: Socio-demographic characteristics of the study population

\begin{tabular}{|c|c|c|c|c|}
\hline \multirow[t]{2}{*}{ Variables } & PIH & Control & \multirow[t]{2}{*}{$\chi^{2}$} & \multirow[t]{2}{*}{ P value } \\
\hline & $n=44(\%)$ & $\mathrm{n}=88(\%)$ & & \\
\hline \multicolumn{5}{|l|}{ Age in years } \\
\hline Mean $\pm S D^{*}$ & $28.7 \pm 6.1$ & $29.6 \pm 4.2$ & 0.991 & $0.323^{* * *}$ \\
\hline \multicolumn{5}{|l|}{$($ Min - Max) } \\
\hline \multicolumn{5}{|l|}{ Marital Status } \\
\hline Single & $9(20.5)$ & $7(8.0)$ & 4.302 & 0.038 \\
\hline Married & $35(79.5)$ & $81(92.0)$ & & \\
\hline \multicolumn{5}{|c|}{ Educational Status } \\
\hline Primary & $4(9.1)$ & $3(3.4)$ & & $0.058^{*}$ \\
\hline Secondary & $16(36.4)$ & $20(22.7)$ & & \\
\hline Tertiary & $24(54.5)$ & $65(73.9)$ & & \\
\hline \multicolumn{5}{|l|}{ Occupation } \\
\hline Housewife & $8(18.2)$ & $13(14.8)$ & & $\mathbf{0 . 0 4 5}^{*}$ \\
\hline Student & $6(13.6)$ & $2(2.3)$ & & \\
\hline Trader & $8(18.2)$ & $21(23.8)$ & & \\
\hline Self-Employed & $6(13.6)$ & $6(6.8)$ & & \\
\hline Civil Servant & $16(36.4)$ & $46(52.3)$ & & \\
\hline
\end{tabular}

**Independent samples $t$-test applied

*Fisher's exact test applied

Table 2: Obstetric and Medical characteristics of respondents

\begin{tabular}{|c|c|c|c|c|}
\hline \multirow[t]{2}{*}{ Variables } & \multirow{2}{*}{$\begin{array}{c}\text { PIH } \\
n=44(\%)\end{array}$} & Control & \multirow[t]{2}{*}{$\chi^{2}$} & \multirow[t]{2}{*}{$P$ value } \\
\hline & & $\mathrm{n}=\mathbf{8 8}(\%)$ & & \\
\hline \multicolumn{5}{|l|}{ Booking Status } \\
\hline Booked & $25(56.8)$ & $75(85.2)$ & 12.89 & 0.000 \\
\hline Unbooked & $19(43.2)$ & $13(14.8)$ & & \\
\hline \multicolumn{5}{|l|}{ Parity } \\
\hline Nulliparous & $15(34.1)$ & $23(26.1)$ & & $0.512^{*}$ \\
\hline Multiparous & $29(65.9)$ & $64(72.8)$ & & \\
\hline Grand Multiparous & $0(0.0)$ & $1(1.1)$ & & \\
\hline \multicolumn{5}{|l|}{ Body Mass Index } \\
\hline Normal & $7(15.9)$ & $19(21.6)$ & 2.386 & 0.496 \\
\hline Overweight & $20(45.5)$ & $33(37.5)$ & & \\
\hline Class I Obesity & $10(22.7)$ & $27(30.7)$ & & \\
\hline Class II Obesity & $7(15.9)$ & $9(10.2)$ & & \\
\hline \multicolumn{5}{|c|}{ Family History of HTN } \\
\hline Yes & $3(6.8)$ & $1(1.1)$ & & $0.108^{*}$ \\
\hline No & $41(93.2)$ & $87(98.9)$ & & \\
\hline \multicolumn{5}{|c|}{ Previous History of PIH } \\
\hline Yes & $11(25.0)$ & $2(2.3)$ & & $<0.001 *$ \\
\hline No & $33(75.0)$ & $86(97.7)$ & & \\
\hline \multicolumn{5}{|l|}{ Mode of Delivery } \\
\hline Vaginal Delivery & $20(45.5)$ & $68(77.3)$ & 13.36 & $<0.001$ \\
\hline Caesarean Section & $24(54.5)$ & $20(22.7)$ & & \\
\hline \multicolumn{5}{|l|}{ Status at Birth } \\
\hline Live birth & $43(97.7)$ & $88(100.0)$ & & $0.333^{*}$ \\
\hline Stillbirth & $1(2.3)$ & $0(0.0)$ & & \\
\hline \multicolumn{5}{|l|}{ Birth Weight } \\
\hline Low Birth weight & $18(40.9)$ & $2(2.3)$ & & $<0.001 *$ \\
\hline Normal Birth weight & $26(59.1)$ & $86(97.7)$ & & \\
\hline \multicolumn{5}{|c|}{ New-born SCBU Admission } \\
\hline Yes & $14(31.8)$ & $10(11.4)$ & 8.250 & 0.004 \\
\hline No & $30(68.2)$ & $78(88.6)$ & & \\
\hline
\end{tabular}

*Fisher's exact test applied 
Table 3: Odds ratio of some characteristics of the respondents

\begin{tabular}{|c|c|c|c|c|c|}
\hline Variables & PIH & Control & Odds Ratio & $95 \%(\mathrm{CI})$ & P value \\
\hline \multicolumn{6}{|c|}{ Marital Status } \\
\hline Single & $9(20.5)$ & $7(8.0)$ & 4.2 & $1.02-12.49$ & 0.009 \\
\hline Married & $35(79.5)$ & $81(92.0)$ & $1.0(\mathrm{RC})$ & & \\
\hline \multicolumn{6}{|c|}{ Previous history of PIH? } \\
\hline Yes & $11(25.0)$ & $2(2.3)$ & 18.1 & $4.4-74.81$ & $<0.001$ \\
\hline No & $33(75.0)$ & $86(97.7)$ & $1.0(\mathrm{RC})$ & & \\
\hline \multicolumn{6}{|c|}{ New-born SCBU Admission } \\
\hline Yes & $14(31.8)$ & $10(11.4)$ & 1.17 & $0.24-5.76$ & 0.041 \\
\hline No & $30(68.2)$ & $78(88.6)$ & & & \\
\hline
\end{tabular}

Model variance: 0.14

RC: Reference Category

Table 4: Mean of Obstetric, Clinical and Foetal parameters

\begin{tabular}{|c|c|c|c|c|c|}
\hline \multirow{2}{*}{ Variables } & PIH & Control & \multirow{2}{*}{$\mathbf{T}$} & \multirow{2}{*}{$95 \%(\mathrm{CI})$} & \multirow{2}{*}{$P$ value } \\
\hline & $n=44(\%)$ & $\mathrm{n}=88(\%)$ & & & \\
\hline Mean Age (years) & $28.7 \pm 6.1$ & $29.6 \pm 4.2$ & 0.991 & $26.8-30.6$ & 0.323 \\
\hline Mean Parity & $1.1 \pm 1.1$ & $1.27 \pm 1.1$ & 0.802 & $1.0-1.5$ & 0.423 \\
\hline Mean Gestational age (weeks) & $37.8 \pm 2.4$ & $39.0 \pm 1.7$ & 3.145 & $38.2-39.0$ & 0.002 \\
\hline Mean BMI $\left(\mathrm{kg} / \mathrm{m}^{2}\right)$ & $29.2 \pm 4.9$ & $29.0 \pm 4.6$ & 0.172 & $28.1-30.0$ & 0.863 \\
\hline Mean Systolic BP (mmHg) & $166.0 \pm 18.1$ & $112 \pm 11.2$ & 20.84 & $125.5-135.4$ & $<0.001$ \\
\hline Mean Diastolic BP (mmHg) & $105.9 \pm 13.0$ & $69.0 \pm 9.2$ & 18.82 & $77.7-84.8$ & $<0.001$ \\
\hline Mean APGAR at 1 minute & $6.7 \pm 1.8$ & $7.6 \pm 1.2$ & 3.486 & $7.1-7.6$ & $<0.001$ \\
\hline Mean APGAR at 5 minutes & $8.4 \pm 1.5$ & $8.9 \pm 1.1$ & 2.374 & $8.5-9.0$ & 0.019 \\
\hline Mean Birth weight (kg) & $2.7 \pm 0.6$ & $3.2 \pm 0.4$ & 6.692 & $3.0-3.1$ & $<0.001$ \\
\hline
\end{tabular}

$t$ - Independent samples t-test

Table 5: Mean serum level of $\alpha F P$ in cases and control

\begin{tabular}{|c|c|c|c|c|c|}
\hline \multirow{2}{*}{ Variables } & PIH & Control & \multirow{2}{*}{$\mathbf{T}$} & \multirow{2}{*}{$95 \%(\mathrm{CI})$} & \multirow{2}{*}{$P$ value } \\
\hline & $n=44(\%)$ & $\mathrm{n}=88(\%)$ & & & \\
\hline$\alpha \mathrm{FP}(\mathrm{ng} / \mathrm{ml})$ & $207 \pm 156.2$ & $165.2 \pm 115.1$ & 1.767 & $156.8-189.6$ & 0.079 \\
\hline
\end{tabular}

$t$ - Independent samples $t$-test

Table 6: Mean serum level of $\alpha F P$ and Severity of PIH

\begin{tabular}{|c|c|c|c|c|c|}
\hline \multirow{2}{*}{ Variables } & Mild & Severe & \multirow{2}{*}{$\mathbf{T}$} & \multirow{2}{*}{$95 \%(\mathrm{CI})$} & \multirow{2}{*}{$P$ value } \\
\hline & $\mathrm{n}=11$ & $n=33$ & & & \\
\hline$\alpha \mathrm{FP}(\mathrm{ng} / \mathrm{ml})$ & $140.8 \pm 109.8$ & $230.0 \pm 164.2$ & 1.673 & $160.2-255.2$ & 0.101 \\
\hline
\end{tabular}

$t$ - Independent samples t-test

Table 7: Serum AFP and type of PIH

\begin{tabular}{|c|c|c|c|c|c|c|}
\hline Variable & $\begin{array}{c}\text { Gestational } \\
\text { Hypertension } \\
\mathbf{n = 1 7}\end{array}$ & $\begin{array}{c}\text { Pre-Eclampsia } \\
\mathbf{n = 1 8}\end{array}$ & $\begin{array}{c}\text { HTN + Superimposed } \\
\text { Pre-Eclampsia } \\
\mathbf{n = 3}\end{array}$ & $\begin{array}{c}\text { Eclampsia } \\
\mathbf{n = 6}\end{array}$ & \multicolumn{2}{|c|}{ Statistical test } \\
\hline & Mean $\pm \mathrm{SD}$ & Mean \pm SD & Mean \pm SD & Mean \pm SD & $\mathrm{F}$ & $\mathrm{p}-$ value \\
\hline & $103.8 \pm 88.5$ & $231.3 \pm 133.1$ & $231.3 \pm 133.1$ & $448.3 \pm 40.4$ & 14.35 & $<0.001$ \\
\hline
\end{tabular}

F-One - way ANOVA

Table 8: Multiple of median for $\alpha$ FP among PIH group

\begin{tabular}{|c|c|c|c|}
\hline \multirow{2}{*}{ Types of PIH } & \multicolumn{2}{|c|}{ P value } \\
\cline { 2 - 4 } & $\begin{array}{c}\mathbf{\leq 2} \mathbf{M o M} \\
\mathbf{n = 3 1}(\boldsymbol{\%})\end{array}$ & $\begin{array}{c}\mathbf{> 2} \text { MoM } \\
\mathbf{n = 1 3}(\boldsymbol{\%})\end{array}$ & \multirow{2}{*}{$0.086^{*}$} \\
\hline Mild & $10(90.9)$ & $1(9.1)$ & \\
\hline Severe & $21(63.6)$ & $12(36.4)$ & \\
\hline
\end{tabular}

*Fishers exact test

MoM-Multiple of Median 
Table 9: Serum AFP as a predictor of severe PIH

\begin{tabular}{|c|c|c|c|}
\hline Contingency table & $\begin{array}{c}\text { Mild PIH } \\
\mathbf{f}(\boldsymbol{\%})\end{array}$ & $\begin{array}{c}\text { Severe PIH } \\
\mathbf{f}(\boldsymbol{\%})\end{array}$ & Total \\
\hline$>2$ MoM AFP & $1(7.7)$ & $12(92.3)$ & $\mathbf{1 3}(\mathbf{1 0 0})$ \\
\hline$<2$ MoM AFP & $10(32.3)$ & $21(67.7)$ & $\mathbf{3 1}(\mathbf{1 0 0})$ \\
\hline Total & $\mathbf{1 1}(\mathbf{2 5})$ & $\mathbf{3 3}(\mathbf{7 5})$ & $\mathbf{4 4}(\mathbf{1 0 0})$ \\
\hline
\end{tabular}

$\mathrm{f}$ - Frequency, $\quad \%$ - row percentage

\begin{tabular}{|c|c|c|c|c|}
\hline Variable & Sensitivity & Specificity & PPV & NPV \\
\hline Severity & $36.0 \%$ & $90.0 \%$ & $92.0 \%$ & $67.7 \%$ \\
\hline
\end{tabular}

Table 10: Foetal outcomes and serum level of $\alpha F P$ among PIH

\begin{tabular}{|c|c|c|c|c|c|c|c|}
\hline \multirow[t]{2}{*}{ Foetal outcomes } & \multicolumn{2}{|c|}{ Serum level of $\alpha \mathrm{FP}$} & \multirow[b]{2}{*}{$\mathbf{T}$} & \multirow[t]{2}{*}{ P value } & \multirow[b]{2}{*}{$\mathbf{R R}$} & \multicolumn{2}{|c|}{$95 \% \mathrm{CI}$} \\
\hline & $\begin{array}{c}<\text { mean level } \\
\mathrm{n}=24(\%)\end{array}$ & $\begin{array}{c}>\text { mean level } \\
\mathbf{n}=\mathbf{2 0}(\%)\end{array}$ & & & & Lower & Upper \\
\hline APGAR & $9.0 \pm 0.6$ & $7.8 \pm 1.8$ & 2.702 & 0.009 & 0.67 & 0.48 & 1.87 \\
\hline Birth weight & $2.9 \pm 0.5$ & $2.4 \pm 0.5$ & 3.423 & 0.001 & 0.25 & 0.10 & 1.64 \\
\hline \multicolumn{8}{|l|}{ Birth Status } \\
\hline Livebirth & $24(100.0)$ & $19(95.0)$ & & $0.455^{*}$ & 1.0 & 0.73 & 7.87 \\
\hline Stillbirth & $0(0.0)$ & $1(5.0)$ & & & & & \\
\hline \multicolumn{8}{|c|}{ Admission into SCBU } \\
\hline Yes & $7(29.2)$ & $7(35.0)$ & & $0.752 *$ & 3.44 & 0.94 & 16.20 \\
\hline No & $17(70.8)$ & $13(65.0)$ & & & & & \\
\hline
\end{tabular}

$t$ - Independent samples $t$-test

*Fishers exact test

Table 11: Bivariate correlation of AFP and BW and Apgar score

\begin{tabular}{|c|c|c|c|c|}
\hline & Control group (Coeff.) & p - value & PIH group (Coeff.) & p - value \\
\hline Birth Weight & -0.20 & 0.075 & -0.47 & $0.001^{* *}$ \\
\hline APGAR at 5 mins & -0.03 & 0.768 & -0.44 & $0.002^{* *}$ \\
\hline
\end{tabular}

**Spearman's rank correlation

\section{Discussion}

The prevalence of pregnancy induced hypertension (PIH) found in this study was $15.3 \%$. This is close to $17 \%$ and $17.2 \%$ that had been reported in Sokoto, Nigeria by Ekele et al, ${ }^{[11]}$ and in Finland $^{[12]}$, respectively. However, it was greater than $10 \%$ and $11.6 \%$ that had been reported from Ibadan and Benin City. ${ }^{[13,14]}$ The factor that may be responsible for the high prevalence of pregnancy induced hypertension in the study area could be due to the fact that it is a referral center, as about $43 \%$ of patients with PIH in this study were unbooked and probably complicated cases.

A positive previous history of PIH was found to be a significant risk factor for developing PIH in this study. (Table 3) Twenty five percent of women in the PIH group as against $2.3 \%$ among the controls had a previous history of PIH. This difference was statistically significant $(\mathrm{P}<0.001)$. This finding is in keeping with a similar study done in northern Nigeria with $36.5 \%$ of PIH cases and $4.7 \%$ of controls having a previous history. ${ }^{[11]}$ Singh et al ${ }^{[11]}$ noted that a positive family history of hypertension was a significant finding in PIH cases when compared with controls. This was not the case in this study. This may be as a result of the larger number of PIH cases in this study compared to that of by Singh et al. $^{[11]}$

The mean birth weight of babies born to women with PIH $(2.7 \pm 0.6 \mathrm{~kg})$ was significantly lower $(\mathrm{p}<0.001)$ than the mean birth weights of babies of normotensive participants $(3.2 \pm 0.4 \mathrm{~kg})$. More than forty percent of PIH cases and only $2.3 \%$ of controls had babies with birth weight of less than $2.5 \mathrm{~kg}$. This was also statistically significant $(\mathrm{P}<0.001)$. Results from this study show that PIH was associated with delivering a low birth weight baby as in some other similar studies. ${ }^{[15,17]}$ The stillborn rate in the PIH group was $2.3 \%$ and $0.0 \%$ in the control group but the difference wasn't significant statistically. This is lower than a rate of $13.8 \%$ reported in a study done in another tertiary center in south western Nigeria $^{[16]}$ and $34.2 \%$ stillborn rate among pre-eclamptics in Olabisi Onabanjo Teaching Hospital, Sagamu, Ogun State, Nigeria. ${ }^{[18]}$ The mean Apgar scores at 1 minute and 5 minutes were both significantly lower in the PIH group than among the normotensive women in this study. Adeosun et $\mathrm{al}^{[16]}$ and Browne et $\mathrm{al}^{[19]}$ also reported significantly lower mean Apgar scores both at 1 minute and 5 minutes of infants born to pre-eclamptics compared to controls. Babies born to women with PIH were also more likely to be admitted into the special care baby unit following delivery compared with controls. This may be a reflection of the increased risk of fetal compromise and growth restriction from placenta hypo-perfusion, and the attendant neonatal morbidity, associated with pregnancy induced hypertension. ${ }^{[18]}$

The mean serum AFP levels were similar in women with PIH and normotensive controls (Table 5). There was also no significant difference in serum AFP levels in women with mild PIH compared with severe PIH (Table 6). These findings are in keeping with reports of a study by Walters et al. ${ }^{[7]}$ However, it is in contrast with finding by Clayton-Hopkins et al. ${ }^{[20]}$ which reported significantly higher mean serum AFP levels in pre-eclamptics than in normotensive controls. However, no eclamptic was recruited into the study by Clayton-Hopkins et al. ${ }^{[20]}$ Pre-eclampsia was also diagnosed in the second half of pregnancy, by an increase in systolic blood pressure of $20 \mathrm{mmHg}$ and diastolic blood pressure of $10 \mathrm{mmHg}$ over a previous reading in two successive visits to the 
physician accompanied by either or both edema and proteinuria, in their study. The different study definition of hypertension in pregnancy used by Clayton Hopkins et al may explain why their findings are not congruent with results of this study.

The serum concentration of AFP varied with the type of pregnancy induced hypertension (Table 7). Women with Gestational hypertension had the least mean serum AFP followed by women with chronic hypertension with superimposed preeclampsia and women with pre-eclampsia. Eclamptics in this study had the highest mean serum concentration of AFP $(448.3 \pm 40.4 \mathrm{ng} / \mathrm{ml})$. Serum AFP was significantly higher in pre-eclampsia and eclampsia than in gestational hypertension (Table 7). This classification mirrors disease pathophysiology, progression and severity, the relatively high levels of serum AFP in pre-eclamptics and eclamptics in this study may suggest the possible use of AFP as markers of severity in PIH.

To predict severe PIH, serum AFP had sensitivity of $36.0 \%$ and specificity of $90.0 \%$ when a value of $2 \mathrm{MoM}$ of study serum AFP was used as cut-off (Table 9).

There was also a highly significant difference $(\mathrm{P}=0.001)$ in the mean birth weights of babies born to mothers with PIH whose serum AFP levels were above the mean $(2.4 \mathrm{~kg} \pm 0.5)$ when compared with those below the mean $(2.9 \mathrm{~kg} \pm 0.5)$ (Table 10$)$. These significant findings of relatively poorer fetal outcome in women with serum AFP above mean values suggests the likelihood of threshold serum levels, above which, correlates with severe disease and adverse fetal outcome in PIH. This further strengthens the possible role of AFP as potential markers of severity in PIH as suggested by other studies. ${ }^{[5,20]}$

Multiple linear regression analysis showed that serum AFP increased as birth weights reduced (Table 12). Serum AFP had significant association with BMI and Apgar scores when adjusted for other variables. Serum AFP showed inverse correlation with baby's birth weight and Apgar score at 5 minutes among women with PIH (Table 11). The inverse correlation of serum AFP with birth weight agrees with findings by Brock et al and Wald et al. ${ }^{[21,22]}$ Puntachai et al ${ }^{[23]}$ noted an inverse correlation of serum AFP with both birth weights and Apgar Scores. These findings suggest elevated serum AFP are biomarkers that can be used to identify women with $\mathrm{PIH}$ at increased risk of adverse fetal outcomes, such as low birth weights and Apgar scores.

\section{Conclusion}

Pregnancy Induced Hypertension occurred in $15.3 \%$ of deliveries. Single mothers and women with a previous history were particularly at risk of developing PIH. Mean maternal serum AFP levels were similar in women with and without PIH. However, maternal serum AFP showed significant correlation with adverse fetal outcome in PIH. Therefore, AFP is a biomarker that can be investigated to identify women at risk of adverse fetal outcome in $\mathrm{PIH}$.

Strengths, limitations and future directives

\section{Strengths}

Patients were followed up to delivery and fetal outcome was determined in the study.

\section{Limitations}

Placenta weight and its possible link with serum AFP were not determined in the study.

\section{Future directives:}

1. Single mothers and women with previous history of PIH should be managed with high index of suspicion for PIH during antenatal care for early diagnosis and management.

2. Maternal serum AFP should be evaluated further as a prognostic marker of fetal outcome in PIH.

3. Large multicentre studies should be done to elucidate the role of serum AFP in PIH to strengthen the aforementioned recommendations.

\section{References}

[1] Watanabe K, Naruse K, Tanaka K, Metoki H, Suzuki Y. Statement of the Society: Outline of Defnition and Classifcation of "Pregnancy induced Hypertension (PIH)". Hypertens Res Pregnancy.2013; 1:3-4. https://www.jstage.jst.go.jp/article/jsshp/1/1/1_3/_pdf

[2] Nwabueze OP, Abanobi O, Nwanko B, Nwabueze A. Occurrence of Pregnancy-Induced Hypertension in selected health facilities in south east Nigeria. International Journal of Tropical Medicine. 2012;7(2):86-92.

[3] Matthiesen L, Berg G, Ernerudh J, Ekerfelt C, Jonsson Y, Sharma S. Immunology of preeclampsia. Chem Immunol Allergy. 2005; 89:49-61. https://www.ncbi.nlm.nih.gov/pubmed/16129952

[4] Gagnon A, Wilson RD. SOGC Genetics Committee. Obstetrical complications associated with abnormal maternal serum markers analytes. SOGC Technical Update no. 217, October 2008. J Obstet Gynaecol Can. 2008; 30(10):918-49. https://sogc.org/wpcontent/uploads/2013/01/gui217CPG0810.pdf.

[5] Allen R, Marleen S, Velauthar L, Harrington K and Aquilina J. The relationship between second trimester alpha fetoprotein levels and adverse pregnancy outcome. Open Journal of Obstetrics and Gynecology, 2013; 3:262-266. doi: 10.4236/ojog.2013.32049. https://file.scirp.org/Html/8-1430332_28666.htm.

[6] Dugoff L.H.J, Nalone F, Vidaver J, Sullivan L. and Canick J. Quad screen as a predictor of adverse pregnancy outcome. Obstetrics and Gynecology. 2005; 106:260-267.

doi:10.1097/01.AOG.0000172419.37410.eb. https://journals.lww.com/greenjournal/Fulltext/2005/080 00/Quad_Screen_as_a_Predictor_of_Adverse_Pregnancy .9.aspx

[7] Walters BN, Lao T, Smith V, et al. Alphafetoprotein elevation and proteinuric pre-eclampsia. British Journal of Obstetrics and Gynaecology. 1985; 92:341-4.

[8] Kang J, Farina A, Park J, Kim S, Kim J, Rizzo N. et al.Down Syndrome biochemical markers and screening for preeclampsia at first and second trimester: Correlation with the week of onset and severity. Prenatal Diagnosis. 2008; 28: 704-709. https://doi.org/10.1002/pd.1997 
[9] Davidson E, Riley S, Roberts S, Shearing C, Groome N. and Martin C. Maternal serum activin, inhibin, human chorionic gonadotrophin and alpha-fetopprotein as second trimester predictors of preeclampsia. British Journal of Obstetrics and Gynaecology. 2003; 110: 543552. https://doi.org/10.1046/j.1471-0528.2003.02037.x

[10] The Apgar score. Committee Opinion No. 644. American College of Obstetricians and Gynaecologists. Obstet Gynecol. 2015; 126:e52-5. https://www.acog.org//media/Committee-Opinions/Committee-on-ObstetricPractice/co644.pdf?dmc=1

[11] Singh S, Ahmed E, Egondu S, Ikechukwu N. Hypertensive disorders in pregnancy among pregnant women in a Nigerian Teaching Hospital. Nigerian Medical Journal. 2014; 55(5):384-8. DOI:10.4103/03001652.140377 .

https://www.researchgate.net/publication/266683345_Hy pertensive_disorders_in_pregnancy_among_pregnant_w omen_in_a_Nigerian_Teaching_Hospital

[12] Hartikainen AL, Riita HA, Paula TR. A cohort study of epidemiological associations and outcomes of pregnancies with hypertensive disorders. Hypertens Pregnancy. 1998; 17:31-41. https://doi.org/10.3109/10641959809072236

[13] Salako BL, Aimakhu CO, Odukogbe AA, Olayemi O, Adedapo KS. A review of hypertensive disorders of pregnancy. African journal of medicine and medical sciences. 2004; 33(2):99-103. https://www.ncbi.nlm.nih.gov/pubmed/15565924\#

[14] Ebeigbe PN, Iberase GO, Aziken ME. Hypertensive disorder in pregnancy: Experience with 442 recent consecutive cases in Benin City, Nigeria. Niger Med J. 2007; 48:94-8. https://www.researchgate.net/publication/266683345_Hy pertensive_disorders_in_pregnancy_among_pregnant_w omen_in_a_Nigerian_Teaching_Hospital

[15] Muti M, Tshimanga M, Notion GT, Bangure D, Chonzi P. Prevalence of pregnancy induced hypertension and pregnancy outcomes among women seeking maternity services in Harare, Zimbabwe. BMC Cardiovascular Disorders. 2015; 15(1):111. https://www.ijcmph.com/index.php/ijcmph/article/view/2 041/1586

[16] Adeosun OG, Charles-Davies MA, Ogundahunsi OA, Ogunlewe J. Maternal and Neonatal Outcomes of Pre-
Eclampsia in African Black Women, South West Nigeria. Greener Journal of Medical Sciences. 2015; 5(4):067-76.

https://pdfs.semanticscholar.org/8a7b/fded1a1bdc5e80e7 43604bf508d3f9bb7542.pdf

[17] Lydakis C, Beevers M, Beevers DG, Lip GY. The prevalence of pre-eclampsia and obstetric outcome in pregnancies of normotensive and hypertensive women attending a hospital specialist clinic. International journal of clinical practice. 2001; 55(6):361-7. https://www.ncbi.nlm.nih.gov/pubmed/11501223.

[18] Sule-Odu Adewale Okanlawon. Maternal and perinatal outcome of patients with preeclampsia in a teaching hospital in southwest Nigeria. Tropical Journal of Obstetrics and Gynaecology. 2015; 32:2. https://www.ajol.info/index.php/tjog/article/view/125010 $/ 114539$.

[19] Browne JL, Vissers KM, Antwi E, Srofenyoh EK, Van der Linden EL, Agyepong IA, et al. Perinatal outcomes after hypertensive disorders in pregnancy in a low resource setting. Tropical Medicine \& International Health. 2015; $20 \quad$ (12):1778-86. https://www.researchgate.net/publication/282360893_Per inatal_outcomes_after_hypertensive_disorders_in_pregn ancy_in_a_low_resource_setting

[20] Clayton-Hopkins JA, Olsen PN, Blake AP. Maternal serum alfa-fetoprotein levels in the pregnancy complicated by hypertension. Prenatal Diagnosis. 1982; 2:47-54. https://doi.org/10.1002/pd.1970020108

[21] Wald NJ, Cuckel HS, Boreham J, Turnbull AC. MATERNAL SERUM ALPHA-FETOPROTEIN AND BIRTH WEIGHT. BJOG: An International Journal of Obstetrics \& Gynaecology. 1980; 87(10):860-3.

[22] Brock DJ, Barron L, Jelen P, Watt M, Scrimgeour JB. Maternal serum-alpha-fetoprotein measurements as an early indicator of low birth-weight. Lancet (London, England). 1977; 2(8032):267-8. url: scihub.tw/10.1016/S0140-6736(77)90952-7

[23] Puntachai P, Wanapirak C, Sirichotiyakul S, Tongprasert F, Srisupundit K, Luewan S, et al. Associations between pregnancy outcomes and unexplained high and low maternal serum alpha-fetoprotein levels. Archives of gynecology and obstetrics. 2015; 292(1):81-5. url: scihub.tw/10.1007/s00404-014-3606-9. 